\title{
The Role of Collective Food Identity in Local Food Demand
}

\author{
Francisco Moreno and Trey Malone \\ Michigan State University, Department of Agricultural, Food, and Resource Economics, Department of \\ Agricultural, Food, and Resource Economics, East Lansing, Michigan
}

Corresponding author: Trey Malone, email: tmalone@msu.edu

\begin{abstract}
Despite a proliferation of articles focused on consumer willingness-to-pay for locally produced foods, few studies have systemically considered the role of food identity in the price premium of local foods. This article uses primary and secondary data to fill that gap. Using data from 9,329 U.S. households, we identify what foods each state considers a part of their collective food identity. We then compare each state's collective food identity to the actual production within the state. Finally, we utilize a discrete choice experiment $(\mathrm{N}=484)$ focused on a state with one such collective food identity to test whether a consumer's preference for local foods is a function of the collective food identity within the state. Results from the open-ended survey suggest that each state connects with their food production in unique ways and that not all state identities are consistent with actual agricultural production. Results from the discrete choice experiment suggest that consumers are more willing to pay a premium for the local food that is a part of their local food identity than for a similar product that is not a part of their local food identity. Our findings imply that future research on consumer preferences for local food systems should consider the relationship between food culture and geography.
\end{abstract}

Keywords: local foods; discrete choice experiment; food identity

JEL Codes: A13; B55; D91; Q13

\section{Introduction}

During the last few decades, consumers in the United States have become increasingly interested in alternative food systems, and local food chains are a key component. Authors such as Wendell Berry (1977) blame the modernization of agriculture for disintegrating farming culture and destroying rural communities. These authors advocate for a move toward reestablishing local cultures with communal memories and care through local and regional agricultural supply chains (DeLind 2011). Partially in response to this heightened consumer interest in "localness," local foods marketing has significantly expanded. For example, between 2007 and 2012, farmers participating in direct-to-consumer marketing outlets increased by 5.5 percent. By 2015, the amount 
sold by these farmers totaled $\$ 8.7$ billion (Thilmany and Woods 2018). Alongside market expansion, academic interest in local foods has extensively increased during the last decade, with an emphasis on consumer perceptions and willingness to pay (Feldmann and Hamm 2015).

The overall objective of this article is to explore the interaction between local food identity and agricultural production. "Local food identity" has been described as the shared food habits formed by people within a defined geographical region, which include regularly used cooking techniques, ingredients, and dishes (Murcott, Belasco, and Jackson 2013). The idea of a geographical cuisine is a tangible feature in a consumer's social identity, making it a key contender in the construction of cultural identity, which requires adopting common community beliefs and practices (Jensen, Arnett, and McKenzie 2011). By extension, residents in each state are likely to consider different food products to be most associated with the state in which they reside, creating important variation in the way consumers are likely to value any local food product.

While prior articles have considered the intersections between food and political identity (Chuck, Fernandes, and Hyers 2016; Malone and Norwood 2019), motherhood (Johnson et al. 2011), authenticity (Giorda 2018), and even African-American pastors (Harmon et al. 2013), fewer studies have considered the interplay between local food production, identity, and consumer demand. One exception is O'Kane (2016), which analyzes local food networks participants' food cultures, finding that their relationship with food was connected to a consumer's relationships with people, place, and time. Food habits perform an important role in the transmission of cultural identity, so it is no surprise that social groups perceive food choices as important for community cohesion (Quintero-Angel, Mendoza, and Quintero-Angel 2019). This local food identity is exemplified on products such as Wisconsin artisanal cheese and New England oysters (Master et al. 2019).

This paper contributes to the literature on local food in three ways. First, we fill a gap in the research in demand for local foods, which generally overlooks the geographic and social connectedness between the studied product and the consumer. Second, we explore the degree of correspondence between a state's collective "local food identity" and the state's local agricultural production. Finally, we use a discrete choice experiment to compare additional premiums in willingness to pay for products connected to a local food identity.

Previous research on local food demand has focused on motivations to purchase as well as the ability of demographics and psychological scales in predicting willingness to pay (Low et al. 2015). Researchers have identified freshness, taste, healthy attitudes, concern about food safety, wish to support local economy, and social desirability as main drivers for local food demand (Low et al. 2015). Despite these key findings, these articles rarely address their sample's association with local food identity. Our findings suggest that a relationship exists between food identity and agricultural production. Furthermore, we find that consumers place a premium on the locally grown foods that they perceive as part of their collective food identity.

The remainder of this article is organized as follows. In the next section, we offer background on the notions and research on food identity and local foods. The third section presents our framework along with our hypotheses. The fourth section explains the data we used. Section five then describes our experiment. Section six presents and interprets our results. The final section concludes with suggestions for further research. 


\section{Background}

Toward the end of the twentieth century, some consumers became concerned about the drastic changes in the traditional agricultural value chain (DeLind 2011). These criticisms raised concerns about long global food chains, increasing worries about untraceable contamination and labor exploitation. According to Laudan (2013, pp. 350), "agrarian and romantic criticisms of modern food processing and mechanized farming" gave birth to the emergence of alternative cuisines. Some consumers came to believe common middle-class cuisines were unhealthful and unethical, leading to public voices calling for a return to home cooking, using of unprocessed and natural foods, support of small farmers, and shorter food chains (Laudan 2013). Within these "countercuisines," "localness" became a valuable attribute (Schnell and Reese 2003).

Academic research on local food demands has increased alongside growth in consumer interest. Of primary interest for us is the relationship between collective food identity and willingness-to-pay estimates for local food. Prior to conducting this analysis, we reviewed the local food literature as it relates to U.S. consumers (see Appendix). Almost 80 percent of these articles focused on unprocessed food items grown at varying levels across different geographic regions. Within this group, fruits and vegetables were the primary category, with a heavy emphasis on apples and tomatoes, followed by steaks and ground beef. Furthermore, there is concern regarding publication bias inflating willingness-to-pay (WTP) estimates (Printezis, Grebitus, and Hirsch 2019). As such, this proliferation of articles suggesting large premiums for local foods could be wrongly interpreted as a positive impact for all types of products in all geographies.

Even more important are the methods with which many researchers measure the notion of localness. Darby et al. (2008) find that consumers assign the same value to different definitions of "local" and that willingness-to-pay for a local attribute is independent from other features. Often, studies focus on geographic boundaries or distance (Printezis, Grebitus, and Hirsch 2019), but the phrase "local foods" can also refer to the connection between a community and its food tradition as well as its farming characteristics (Bazzani \& Canavari, 2017). Thus, collective food identity is entwined with the development of localness as a valuable attribute. In parallel form, the value of localness is likely to be higher when the considered food is associated with a place's values and cultural heritage, leading to feelings of cultural belonging (Schmitt, Dominique, and Six 2018). As such, a region's food identity is likely to include local foods, and a local food item associated with a region's cultural background is perceived as an authentic part of the region's food identity.

As Printezis, Grebitus, and Hirsch (2019) note, findings within this growing research area are mixed and ambiguous. This is perhaps unsurprising, as the research on local food demand covers topics that include consumer perceptions, motivations to purchase, and willingness to pay (Feldmann and Hamm 2015). Rather than a genuine preference for them, local food premiums can be conditioned on distrust of governmental food agencies and polarization against conventional products (Costanigro et al. 2014). Meas et al. (2015), exploring distinct organic and local definitions, found evidence that organic and local attributes are perceived as substitutes and that a food's origin from a small farm is a substitute for local and organic attributes, supporting the beliefs that local demand is motivated by associated values rather than geographic proximity itself. Notwithstanding the growing research in local foods, we were not able to find an article addressing the role of food identity in willingness-to-pay. In the context of understanding localness as a more complex notion than distance, the absence of an 
empirical approach to the role of food identity on local food demand is a gap worth exploring.

\section{Theoretical Framework}

Each alternative within a food choice scenario generates distinct levels of satisfaction (or utility), according to their attributes, the individual's characteristics, and the choice context (Hensher, Rose, and Greene 2015). We follow the discrete choice model from McFadden (1973) where an individual ( $n^{\text {th }}$ decision maker), in a food choice situation ( $s^{\text {th }}$ choice situation), perceives a utility level for a food item ( $j^{\text {th }}$ alternative), which we state mathematically as:

$$
U_{n s j}=X_{n s} \beta_{j}+a_{n s j}
$$

where $X$ is a vector of attributes that change with the choice situation and the decision maker, $\beta_{j}$ is a vector of parameters that change with the alternative, and $a_{n s j}$ contains all the unobserved variables that impact on the utility level generated by the considered alternative. In this case, $\beta_{j \text {, local }}$ can be interpreted as the marginal impact on utility of "local."

The value of a local food item is likely to be higher when the considered food is associated with a place's values and cultural heritage (e.g., local food identity). In other words, ceteris paribus, we expect consumers to choose a local food item that belongs to their food identity over one that is simply local. Residents of each geographic region are likely to have a unique consortium of foods that are representative of their collective food identity. Accordingly, respondents within the same state are likely to share similar opinions when asked about foods that are a part of their collective food identity. This relationship is likely to be connected to that state's agricultural production (Bazzani and Canavari 2017).

The relationships identified by the prior literature lead us to three testable hypotheses. First, we hypothesize that consumers place a larger premium on locally grown foods that they perceive as a part of their collective food identity. Therefore, we expect to observe that the marginal utility of localness is higher for a choice alternative that is part of the respondent's collective food identity. Second, we hypothesize that the heterogeneity of consumer preferences is likely to influence willingness-to-pay estimates. As such, we expect that estimating a unique "local" attribute for each product in the choice set is likely to fit the discrete choice data better than estimating a homogenous "local" attribute. Finally, we hypothesize that production volume is likely to influence a consumer's utility associated with their local food identity. That is, commodities that are grown more in a state are also likely to capture a higher willingness-to-pay for localness.

\section{Data and Methods}

Data were collected in two steps to address our hypotheses. To identify what foods are a part of each state's collective food identity, we first gathered primary data in collaboration with the Food Demand Survey (e.g., the FooDS [Lusk, 2017]). The FooDS was an online survey conducted by the Department of Agricultural Economics of Oklahoma State University and delivered monthly from 2013 to 2017 to samples of over 1,000 U.S. consumers. Its primary purpose was to track consumer preferences and sentiments 
on the safety, quality, and price of food consumed at home and away from home, as well as consumer awareness of food-related issues and events. Over nine months of the survey in 2016-2017, we asked 9,329 U.S. food consumers about foods that they consider a part of their state's local food identity. Using an open-ended question format, we asked:

Many people believe their state is associated with a particular type of food. In the space below, please list one or more foods that you believe is most associated with the state in which you currently reside.

One might presume that there is a strong relationship between a state's food identity and what they produce the most of. To test this, we compared the cleaned, ordered, and grouped FooDS responses to each state's top three answers to each state's top three crops in terms of cash receipts reported in the Farm Income and Wealth Statistics of the USDA-Economic Research Service (2018). After merging survey responses and agricultural production, we compared the top three participant responses for their state's food identity and the top three state's agricultural commodities (Table 1).

Almost 90 percent of the states in the sample exhibit a relationship between their indicated food identity and the top three agricultural commodities produced within the state, though that relationship varies significantly. For example, the foods that Californians identified as representative of their home state differ entirely. By contrast, the three foods identified by participants from Wisconsin coincided perfectly with the top three most produced agricultural commodities in Wisconsin. Despite being among the main agricultural products for 21 states, dairy is only mentioned as a main item in the top-three food identity foods for Wisconsin, Rhode Island, and Vermont. Similarly, food of an international origin (e.g., Mexican and Italian) was identified as part of the collective food identities of nine states. As an example, in New Mexico chilies, beef, and Mexican food are within the top foods in the survey, whereas dairy, beef cattle, and pecans are the main agricultural products.

There is generally a weaker relationship between production in states with significant specialty crop production and food identity. For example, the five food products most identified by Michiganders as most representative of their home state were cherries, apples, beef, corn, and dairy, while the five agricultural commodities most produced by Michiganders were dairy products, corn, soybeans, cattle and calves, and hogs.

\section{Experimental Design}

We utilize a discrete choice experiment to test if consumers place a premium on foods that are part of their collective food identity. Similar to Lusk (2017), we ask participants to choose between substitutable products at varying prices that are readily available at a grocery store. We selected Michigan, as the state is capable of growing many specialty crops commercially. Our experimental design follows a $2 \times 2$ format where we focus on the interaction between local food identity and local agricultural production (Table 2).

Based on USDA cash receipts data, we chose cherries, as it is both a key agricultural product in Michigan (\$67,069,000 in 2015 cash receipts) and a part of Michigan's collective food identity ( $1^{\text {st }}$ most frequent answer in FooDS for Michigan). We then chose strawberries, which is also part of Michigan's collective food identity $\left(8^{\text {th }}\right.$ most frequent answer in FooDS for Michigan), but producers do not grow a large volume of them (\$4,375,000 in 2015 cash receipts). We then identified grapes as a commodity produced in Michigan but not listed as part of Michigan's collective food identity $(\$ 25,734,000$ in 
Table 1. Food Identity Responses Main Agricultural Products According to Cash Receipts by State

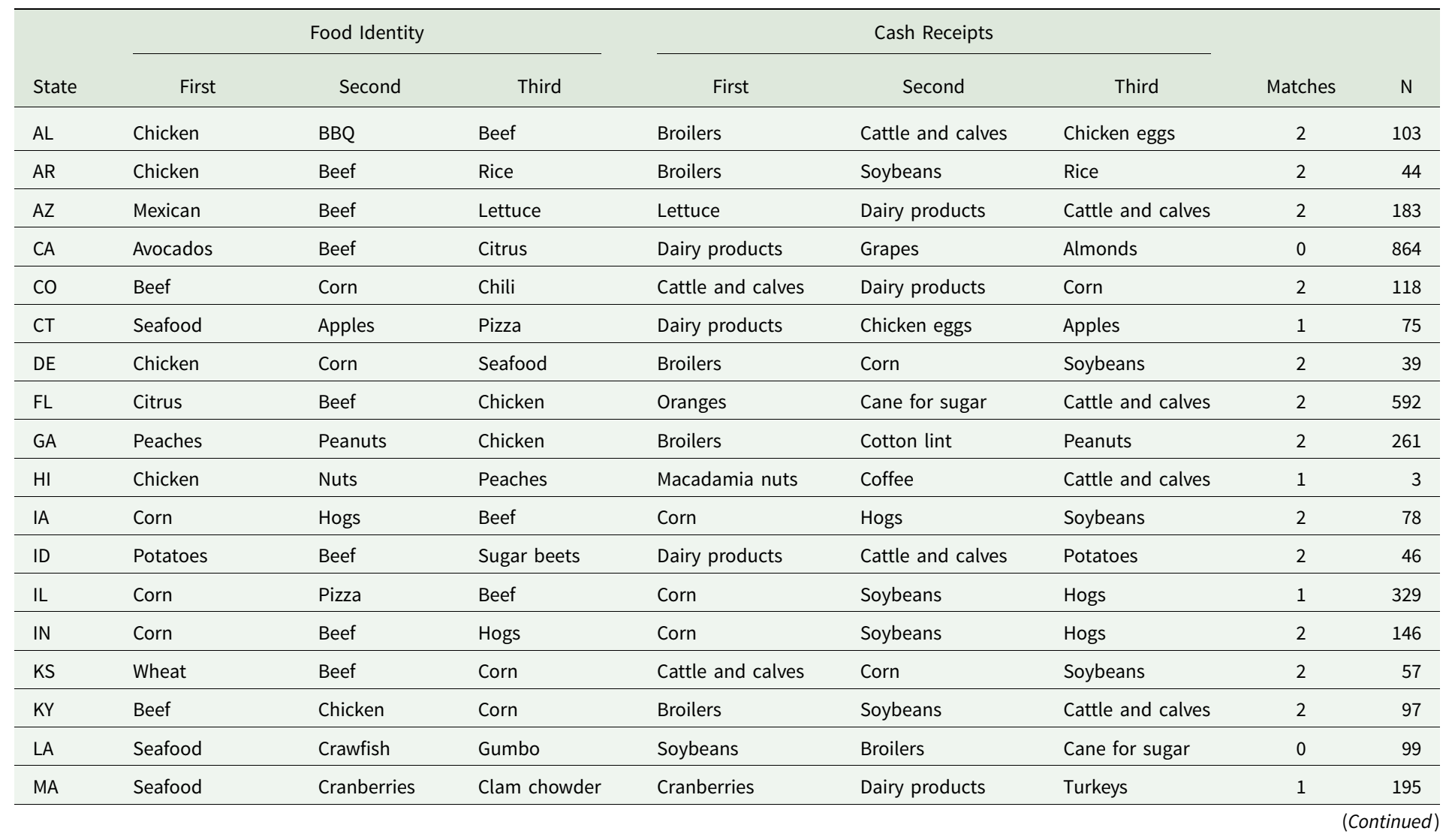


Table 1. (Continued.)

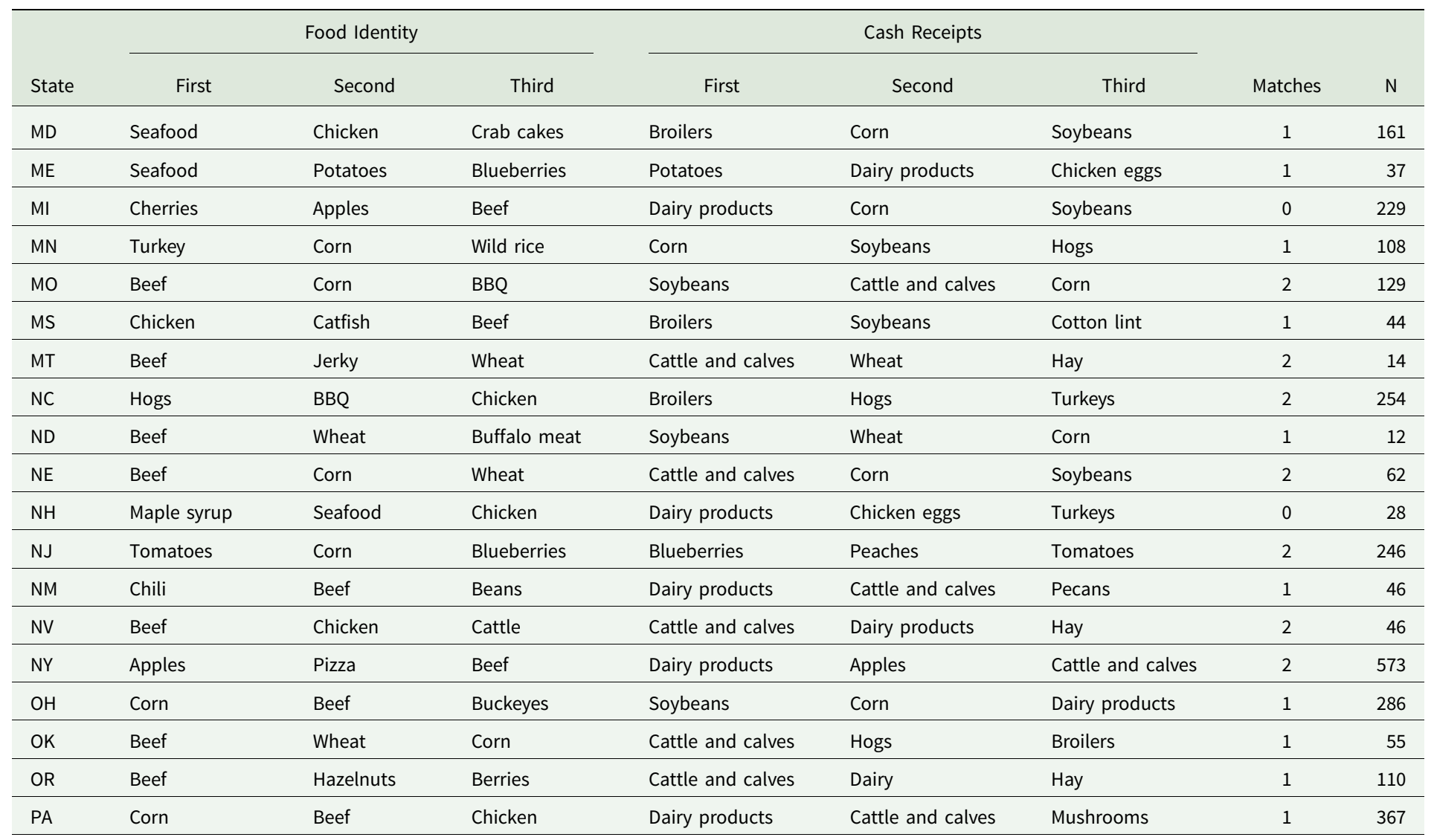




\begin{tabular}{|c|c|c|c|c|c|c|c|c|}
\hline RI & Seafood & Chicken & Dairy & Chicken eggs & Turkeys & Dairy products & 1 & 31 \\
\hline SC & Peaches & Chicken & Beef & Broilers & Corn & Cattle and calves & 2 & 96 \\
\hline SD & Beef & Corn & Hogs & Cattle and calves & Corn & Soybeans & 2 & 17 \\
\hline $\mathrm{TN}$ & $\mathrm{BBQ}$ & Chicken & Beef & Soybeans & Cattle and calves & Broilers & 2 & 130 \\
\hline $\mathrm{TX}$ & Beef & $\mathrm{BBQ}$ & Mexican & Cattle and calves & Cotton lint & Broilers & 1 & 504 \\
\hline UT & Honey & Beef & Fry sauce & Cattle and calves & Dairy & Hay & 1 & 58 \\
\hline VA & Ham & Peanuts & Chicken & Broilers & Cattle and calves & Dairy products & 1 & 176 \\
\hline VT & Dairy & Maple syrup & Honey & Dairy products & Cattle and calves & Maple products & 2 & 9 \\
\hline WA & Apples & Beef & Potatoes & Apples & Dairy & Potatoes & 1 & 174 \\
\hline WI & Dairy & Beef & Corn & Dairy products & Cattle and calves & Corn & 3 & 172 \\
\hline WV & Pepperoni rolls & Beef & Apples & Cattle and calves & Broilers & Turkeys & 1 & 31 \\
\hline WY & Beef & Buffalo & Sugar & Cattle and calves & Hay & Hogs & 1 & 11 \\
\hline
\end{tabular}

Note: Food identity responses are based on answers to the question, "Many people believe their state is associated with a particular type of food. In the space below, please list one or more foods that you believe is most associated with the state in which you currently reside." Data were collected in collaboration with the Oklahoma State University Food Demand Survey (Lusk 2017). 

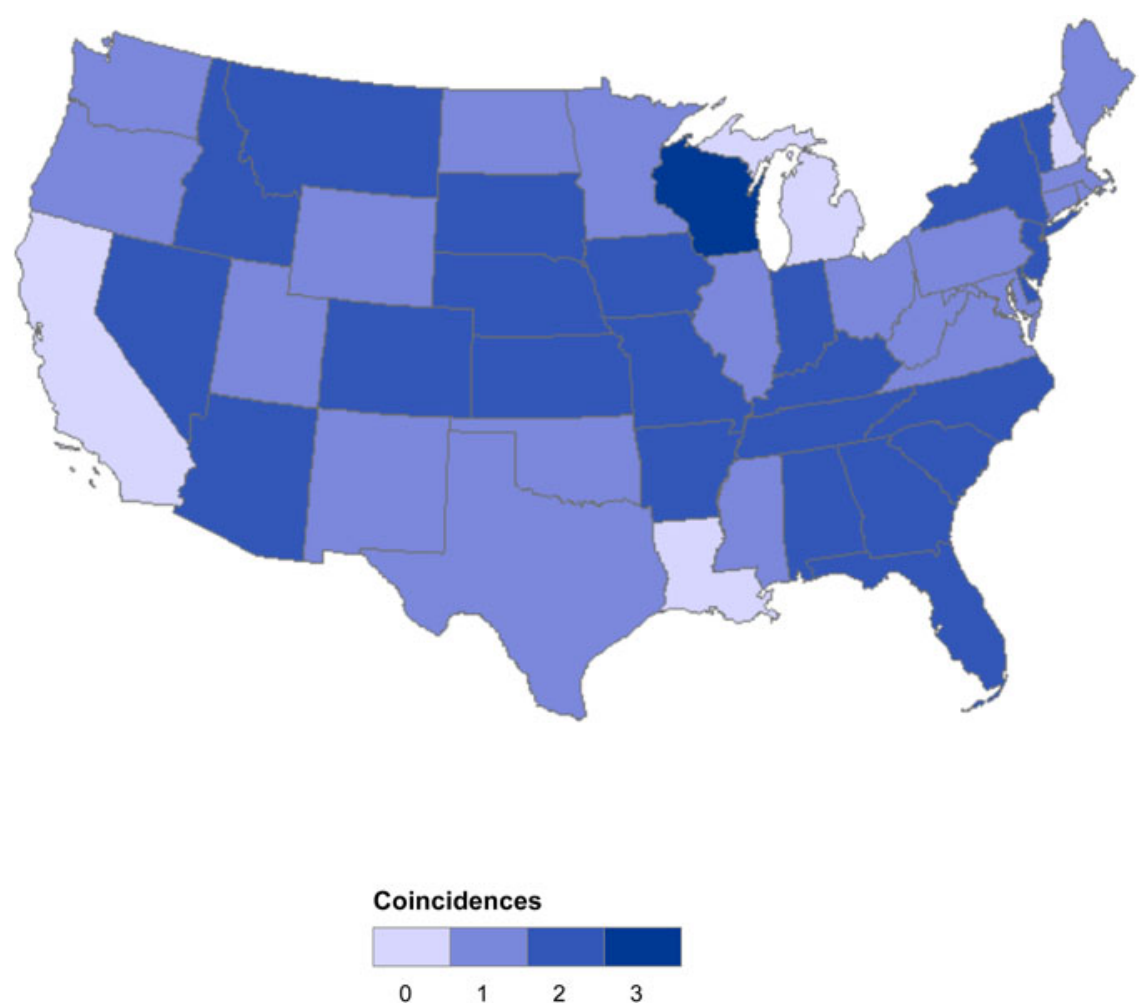

Figure 1. Comparison of Collective Food Identity and Local Agricultural Production Note: Coincidences signify the overlap between the three main answers in the Food Demand Survey and three main local agricultural products measured by USDA cash receipts.

2015 cash receipts). Finally, we included blackberries, as it is a substitutable product that is not significantly grown in Michigan nor is it a part of Michigan's food identity. Both grapes and blackberries were not mentioned at all as part of Michigan's collective food identity by the respondents of the FooDS.

\section{Survey Design}

Survey data were collected via Amazon's crowdsourcing platform Mechanical Turk (MTurk) where researchers submit surveys to individuals who are compensated a menial fee upon completion. The use of MTurk participants is increasingly popular for academic work (Dupuis, Endicott-Poposky, and Crossler 2013), with thousands of studies having been conducted via MTurk data (Hitlin 2016). The platform provides easy access to a large, stable, and diverse subject pool (Mason \& Suri, 2012). Prior research suggests that MTurk samples are often preferred to alternative sampling methods (Berinsky, Huber, and Lenz 2012) in part because MTurk participants respond to surveys more attentively than alternative panels (Hauser and Schwarz 2016).

The Qualtrics ${ }^{\circledast}$ survey was organized into two parts. First, we conducted the discrete choice experiment based on an orthogonal fractional factorial design that was developed via $\mathrm{SAS}^{\oplus}$, generating 16 individual choice scenarios. The attributes considered in the 
Table 2. Experimental Design to Identify the Effects of Local Production and Collective Food Identity

\begin{tabular}{|c|c|c|c|}
\hline & & \multicolumn{2}{|c|}{$\begin{array}{l}\text { Does it belong to Michigan's } \\
\text { food identity? }{ }^{2}\end{array}$} \\
\hline & & Yes & No \\
\hline \multirow[t]{2}{*}{ Is it commercially produced at scale in Michigan $?^{1}$} & Yes & Cherries & Grapes \\
\hline & No & Strawberries & Blackberries \\
\hline
\end{tabular}

${ }^{1}$ Defined as being one of the top 20 cash receipts defined by the USDA.

${ }^{2}$ Defined as being one of the top 5 collective food identity by Michigan survey participants.

design were price and "localness," with each price level being set based on observed grocery store prices. ${ }^{1}$ Participants were randomly assigned 8 out of the 16 scenarios so each respondent was exposed to eight choice situations where the alternatives had two price levels and a local/not local label. Figure 2 presents an example of the discrete choice questions presented to participants.

The second portion of the survey focused on demographics, including gender, age, and income levels. This portion of the survey also asked for information about food behavior. As a check on the collective food identity items from the FooDS, we also included the same open-ended collective food identity question.

\section{Results}

Discrete choice data were collected in the summer of 2019. We obtained 508 responses, from which 484 were completed. Similar to the prior survey, participants identified cherries (33 percent) and strawberries (4 percent) as a part of their collective food identity. Participant demographic information is summarized in Table 3. Sixty-one percent of respondents identified as female, while females comprise 51 percent of the Michigan population (U.S. Census Bureau 2019). Almost 67 percent of the respondents were between 25 and 44 years old, whereas this same age group represents 24 percent of the Michigan population (U.S. Census Bureau 2019). The sample was equally divided between single and married participants, while 48 percent of Michiganders are married (U.S. Census Bureau 2019). The sample is also overeducated, as 36 percent of the sample have earned a four-year college degree, whereas only 17 percent of Michiganders have attained a bachelor's degree (U.S. Census Bureau, 2019). In addition, 37.2 percent and 58.5 percent of our sample earned an annual income below $\$ 40,000$ and $\$ 60,000$, respectively, while the median individual income for a person 25 years and over is $\$ 36,396$ in Michigan (U.S. Census Bureau 2019).

Since each of the 484 participants responded to eight discrete choices, we conduct our analysis with 3,872 unique choices. Most respondents chose grapes and strawberries (31 percent and 35 percent, respectively). We fit random parameter logit models in the NLOGIT $^{\oplus}$ software with "no choice" as the base alternative. The first model considers a homogenous "local" parameter for all the alternatives, while the second model assumes a heterogeneous "local" parameter for each alternative. Using these estimates, we make two important comparisons. First, we test whether heterogeneous "local" attributes fit the data better than a single "local" parameter. This finding would signal that the

\footnotetext{
${ }^{1} \mathrm{~A}$ table of product prices can be found in Table A2 in the Appendix.
} 


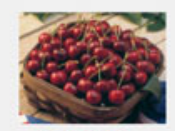

Cherries

$\$ 7.24 / \mathrm{lb}$

Grown in

Michigan
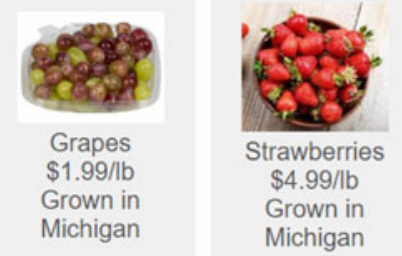

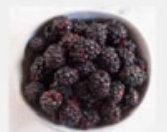

Blackberries

$\$ 2.49 / 6$ oz

Grown

outside

Michigan
If these were

the only

options, I

would

choose

something

else to eat.

Figure 2. Example of the Discrete Choice Questions Presented to Participants

value of "localness" varies across products. Second, we test whether the utility associated with local is higher for products that are a part of Michigan's collective food identity.

Table 4 shows the results from the random parameter logit models. The price coefficient is negative and statistically significant, indicating that utility decreases when prices increase. The alternative-specific constants for cherries, grapes, strawberries, and blackberries are positive and statistically significant, indicating that these alternatives are preferred to choosing nothing at all. Strawberries are the most preferred alternative, followed by grapes. We find that a model with heterogeneous "local" parameters fits the data better than a single "local" parameter since the McFadden Pseudo $\mathrm{R}$-squared of the former is higher.

When we consider the 95 percent confidence intervals of our estimates of the RPL model, a higher marginal utility by localness for a product identified as part of Michigan food identity is only observed within products that are largely produced within the state (Figure 3). In this last group, the 95 percent confidence intervals for the local attribute for cherries and grapes do not overlap ([2.15, 2.99] and [1.47, $1.86])$, while in the group that are not main agricultural products these intervals for strawberries and blackberries do overlap ([1.92, 2.31] and [1.74, 2.26]).

From the parameter estimates for localness, we estimate willingness-to-pay for local (WTPL) by dividing them by the negative of the price coefficient estimate. Following the previous results, WTPL is higher for the product that is identified as part of Michigan's collective food identity both within the group of highly locally produced items and those that are not. In the case of highly produced agricultural products, cherries (part of Michigan's food identity) have a higher WTPL than grapes ( $\$ 4.43$ and $\$ 2.88$, respectively). Moreover, the local attribute represents a 56.6 percent price premium for fresh cherries and 44.7 percent for grapes. In the case of products that are not main agricultural products, strawberries (part of Michigan's food identity) have a higher WTPL than blackberries (\$3.66 and $\$ 3.43$, respectively).

These results are consistent with the notion that valuation for foods perceived as part of collective food identity is likely to be interconnected with local agricultural production. Laudan (2013) and Bazzani and Canavari (2017) stressed that an item belonging to a community's local food identity has strong link to the community's food and agricultural production. Therefore, an item that is both part of the collective food identity and is largely locally produced could be valued more than an item that does not have those two features. This could explain why localness premium is significantly higher for 
Table 3. Summary of Demographics in the Discrete Choice Experiment

\begin{tabular}{|c|c|c|}
\hline Variable & Value & Percent \\
\hline \multirow[t]{2}{*}{ Gender } & Female & 60.5 \\
\hline & Male & 39.5 \\
\hline \multirow[t]{6}{*}{ Age } & $18-24$ years old & 13.6 \\
\hline & 25-34 years old & 39.1 \\
\hline & $35-44$ years old & 28.1 \\
\hline & $45-54$ years old & 12.8 \\
\hline & $55-64$ years old & 3.9 \\
\hline & $65-74$ years old & 2.5 \\
\hline \multirow[t]{4}{*}{ Marital status } & Divorced & 6.6 \\
\hline & Married & 46.3 \\
\hline & Separated & 0.8 \\
\hline & Single & 46.3 \\
\hline \multirow[t]{5}{*}{ People living in the household } & 1 & 15.9 \\
\hline & 2 & 32.9 \\
\hline & 3 & 18.6 \\
\hline & 4 & 19.6 \\
\hline & 5 or more & 13.0 \\
\hline \multirow[t]{2}{*}{ Children under age 12 in the household } & No & 64.5 \\
\hline & Yes & 35.5 \\
\hline \multirow[t]{7}{*}{ Education } & Less than High School & 0.6 \\
\hline & High School/GED & 10.1 \\
\hline & Some College & 25.4 \\
\hline & 2-Year College Degree (Associates) & 12.6 \\
\hline & 4-Year College Degree (BA, BS) & 36.4 \\
\hline & Master's Degree & 13.0 \\
\hline & Professional Degree (Ph.D., J.D., M.D.) & 1.9 \\
\hline \multirow[t]{8}{*}{ Income } & Less than $\$ 20,000$ & 14.3 \\
\hline & $\$ 20,000-\$ 39,999$ & 22.9 \\
\hline & $\$ 40,000-\$ 59,999$ & 21.3 \\
\hline & $\$ 60,000-\$ 79,999$ & 19.2 \\
\hline & $\$ 80,000-\$ 99,999$ & 10.3 \\
\hline & $\$ 100,000-\$ 119,999$ & 6.0 \\
\hline & $\$ 120,000-\$ 139,999$ & 2.3 \\
\hline & $\$ 140,000$ or greater & 3.7 \\
\hline \multirow[t]{3}{*}{ Race } & Caucasian & 80.6 \\
\hline & African American & 10.9 \\
\hline & Other & 8.5 \\
\hline
\end{tabular}


Table 4. Random Parameter Logit Model Estimates

\begin{tabular}{|c|c|c|c|c|}
\hline & \multicolumn{2}{|c|}{ Homogenous Localness } & \multicolumn{2}{|c|}{ Heterogeneous Localness } \\
\hline & Coefficient & Std. Dv. & Coefficient & Std. Dv. \\
\hline \multirow[t]{2}{*}{ Cherries } & $2.57^{\star \star \star}$ & $2.61^{\star \star \star}$ & $1.97^{\star \star \star}$ & $2.78^{\star \star \star}$ \\
\hline & $(0.28)$ & $(0.21)$ & $(0.35)$ & $(0.23)$ \\
\hline \multirow[t]{2}{*}{ Grapes } & $1.88^{\star \star \star}$ & $1.66^{\star \star \star}$ & $2.07^{\star \star \star}$ & $1.61^{\star \star \star}$ \\
\hline & $(0.13)$ & $(0.11)$ & $(0.13)$ & $(0.11)$ \\
\hline \multirow[t]{2}{*}{ Strawberries } & $2.76^{\star \star \star}$ & $1.48^{\star \star \star}$ & $2.67^{\star \star \star}$ & $1.50^{\star \star \star}$ \\
\hline & $(0.14)$ & $(0.10)$ & $(0.15)$ & $(0.10)$ \\
\hline \multirow[t]{2}{*}{ Blackberries } & $1.30^{\star \star \star}$ & $1.63^{\star \star \star}$ & $1.27^{\star \star \star}$ & $1.64^{\star \star \star}$ \\
\hline & $(0.15)$ & $(0.12)$ & $(0.17)$ & $(0.13)$ \\
\hline \multirow[t]{2}{*}{ Price } & $-0.58^{\star \star \star}$ & & $-0.58^{\star \star \star}$ & \\
\hline & $(0.02)$ & & $(0.02)$ & \\
\hline \multirow[t]{2}{*}{ Local Label } & $1.98^{\star \star \star}$ & & & \\
\hline & $(0.02)$ & & & \\
\hline \multirow[t]{2}{*}{ Local_Cherries } & & & $2.57^{\star \star \star}$ & \\
\hline & & & $(0.22)$ & \\
\hline \multirow[t]{2}{*}{ Local_Grapes } & & & $1.67^{\star \star \star}$ & \\
\hline & & & $(0.09)$ & \\
\hline \multirow[t]{2}{*}{ Local_Strawberries } & & & $2.12^{\star \star \star}$ & \\
\hline & & & $(0.09)$ & \\
\hline \multirow[t]{2}{*}{ Local_Blackberries } & & & $1.99^{\star \star \star}$ & \\
\hline & & & $(0.13)$ & \\
\hline Akaike information criterion & \multicolumn{2}{|c|}{8,633} & \multicolumn{2}{|c|}{8,617} \\
\hline
\end{tabular}

484 participants completed the survey, generating 3,872 unique choice observations.

Parameters can be interpreted as the relative change in happiness derived from choosing a product with the specified attribute.

Numbers in parentheses are standard errors.

${ }^{\star \star \star},{ }^{\star \star}$, and ${ }^{*}$ indicate significance at 1 percent, 5 percent, 10 percent levels.

a product that is part of Michigan's food identity only within products that are largely produced within the state. Cherries (part of Michigan's food identity) and grapes are largely produced within the state and we found that cherries have a significant higher premium for localness than grapes. In contrast, strawberries (part of Michigan's food identity) and blackberries are not largely produced within the state, and their respective premiums were statistically similar. Thus, the results of our discrete choice experiment provide support for the notion that, at least for Michigan, consumers are likely to place a higher premium on the locally grown foods that they perceive as part of their collective food identity. 


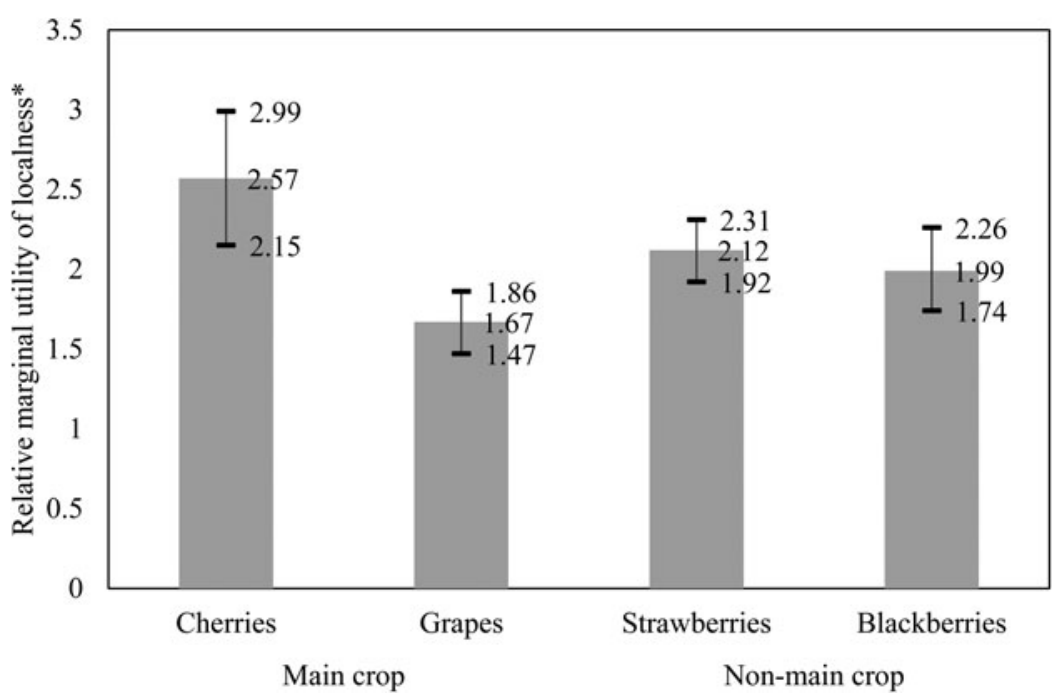

Figure 3. Mean Parameter Estimates for the Value of "Localness" for Each Alternative Notes: Marginal utility of local attribute with respect to the alternative of not choosing nothing at all. Can be interpreted as an empirical value of localness for each product.

\section{Conclusion}

American consumers have recently paid more attention to "localness" as an important food product attribute than they used to. Despite the growing literature, researchers have not yet thoroughly addressed the relationship between local foods and local food identity. This study explored that interaction by evaluating the degree of correspondence between a state's collective "local food identity" and the state's local agricultural production as well as the role of belonging to local food identity in willingness to pay for localness. Using primary data from Michigan consumers, we found a positive relationship between collective food identity, agricultural production, and consumer preferences for localness. We found that consumers place varying premiums on different types of locally grown foods. More importantly, this article supports the notion that consumers place a premium on the locally grown foods that they perceive as part of their collective food identity. However, this premium occurs only within products that are largely locally produced. These results begin to fill a gap in the local food literature, as they suggest that collective food identity is an important attribute worth considering in future studies.

Since our data was gathered in an online survey that overrepresented certain population groups, future studies might utilize secondary data or non-hypothetical experimental data. It could also be that respondents were willing to pay more for local cherries because they are perceived to simply be of higher quality. If respondents believed Michigan provides a unique environment for producing tastier cherries, the higher value they assign to it might be somewhat confounded. There is no clear reason why consumers would have the agronomic knowledge necessary for understanding which growing conditions are best for cherries relative to grapes, strawberries, and blackberries. However, if there is a general belief that local cherries 
have higher quality due to other reasons like marketing campaigns, further research would have to control for quality to consistently estimate the value of being part of the collective food identity. This is particularly problematic, as perceptions of fruit quality are not always vertically defined but are often use-specific. For example, Balaton cherries are generally considered more preferred to Montmorency for fresh consumption, though there is no obvious reason why all consumers would follow this preference ordering.

Previous studies have shown that a premium for localness could be confounded with other important variables such as perceived freshness or organic preferences (Low et al. 2015; Donaher and Lynes 2017). Thus, any willingness-to-pay estimates for localness are likely to have some bias. Because this study compared the estimates of willingness-to-pay for localness of products that are part of Michigan's local food identity with products that are not, we believe we have largely side-stepped this potential bias. That is, the potential confound between localness and other attributes should happen for all products we are considering. Nonetheless, this article supports our hypothesis that an important relationship exists between collective food identity and utility associated with localness.

These findings have value for public policy and food marketing decisions. Policymakers have invested over $\$ 1$ billion dollars in local foods promotion over the past few years, yet many local food systems continue to struggle (Thilmany and Woods 2018). Given these massive investments, awareness of the variables that increase the value assigned by consumers could be used to improve targeting and finding efficient ways to invest those funds. In this case, local food dollars might be more appropriately used to promote a community's preexisting local food culture as it relates to consumers' collective food identities. Similarly, food marketers might benefit by expanding their efforts to distinguish and promote their local labels as they link with each region's food identity. For example, the Michigan tart cherry industry hosts an annual National Cherry Festival each year in Northern Michigan, highlighting the industry's linkages to the state's collective identity. Events that emphasize, or raise, the degree of identification with foods could then imply a higher willingness to pay when grown locally.

\section{References}

Adalja, A., J. Hanson, C. Towe, and E. Tselepidakis. 2015. "An Examination of Consumer Willingness to Pay for Local Products." Agricultural and Resource Economics Review 44: 253-274.

Bazzani, C., and M. Canavari. 2017. "Is Local A Matter of Food Miles or Food Traditions?" Italian Journal of Food Science 29: 505-517.

Berinsky, A., G. Huber, and G. Lenz. 2012. "Evaluating Online Labor Markets for Experimental Research: Amazon.com's Mechanical Turk." Political Analysis 351-368.

Bernard, J.C., and Y. Liu. 2017. "Are Beliefs Stronger than Taste? A Field Experiment on Organic and Local Apples." Food Quality and Preference 61: 55-62.

Berry, W. 1977. The Unsettling of America. Berkeley: Counterpoint Press.

Bosworth, R., D. Bailey, and K. Curtis. 2015. "Consumer Willingness to Pay for Local Designations: Brand Effects and Heterogeneity at the Retail Level." Journal of Food Products Marketing, 21: 274-292.

Brown, C. 2003. Consumers' Preferences for Locally Produced Food: A Study in Southeast Missouri. American Journal of Alternative Agriculture 18: 213-224.

Bruno, C.C., and B.L. Campbell. 2016. "Students' Willingness to Pay for More Local, Organic, Non-GMO and General Food Options." Journal of Food Distribution Research 47: 32-48. 
Byrd, E., N. Widmar, and M. Wilcox. 2018. "Are Consumers Willing to Pay for Local Chicken Breasts and Pork Chops?” Journal of Food Products Marketing 24: 235-248.

Carpio, C.E., and O. Isengildina-Massa. 2009. "Consumer Willingness to Pay for Locally Grown Products: The Case of South Carolina." Agribusiness 25: 412-426.

Chen, J., M.C. Haws, Q.S. Fong, and P. Leung. 2017. "Locally Grown Oysters in Hawaii: Chef Preference and Local Premium?" Journal of the World Aquaculture Society 48: 972-980.

Chuck, C., S. Fernandes, and L. Hyers. 2016. "Awakening to The Politics of Food: Politicized Diet as Social Identity." Appetite 107: 425-436.

Costanigro, M., S. Kroll, D. Thilmany, and M. Bunning. 2014. "Is it Love for Local/Organic or Hate for Conventional? Asymmetric Effects of Information and Taste on Label Preferences in an Experimental Auction." Food Quality and Preference 31: 94-105.

Costanigro, M., D. Thilmany, S. Kroll, and G. Nurse. 2011. "An In-Store Valuation of Local and Organic Apples: The Role of Social Desirability." Agribusiness 27: 465-477.

Darby, K., M.T. Batte, S. Ernst, and B. Roe. 2008. "Decomposing Local: A Conjoint Analysis of Locally Produced Foods." American Journal of Agricultural Economics 90: 476-486.

DeLind, L. 2011. "Are Local Food and the Local Food Movement Taking Us Where We Want to Go? Or Are We Hitching Our Wagons to the Wrong Stars? Agriculture and Human Values 28: 273-283.

Dobbs, L., K. Jensen, M. Leffew, B. English, D. Lambert, and C. Clark. 2016. "Consumer Willingness to Pay for Tennessee Beef." Journal of Food Distribution Research 47: 38-61.

Donaher, E., and J. Lynes. 2017. "Is local produce more expensive? Challenging perceptions of price in local food systems." Local Environment 22: 746-763.

Dupuis, M., B. Endicott-Popovsky, and R. Crossler. 2013. "An Analysis of the Use of Amazon's Mechanical Turk for Survey Research in the Cloud." In ICCSM2013-Proceedings of the International Conference on Cloud Security Management: ICCSM.

Everett, C., K.L. Jensen, C. Boyer, and D.W. Hughes. 2018. "Consumers' Willingness to Pay for Local Muscadine Wine." International Journal of Wine Business Research 30: 58-73.

Fang, X., H. Huang, and P. Leung. 2017. "Competitiveness of Local Food: An Empirical Analysis of the Tomato Market Dynamics." International Food and Agribusiness Management Review 21: 89-100.

Feldmann, C., and U. Hamm. 2015. "Consumers' Perceptions and Preferences for Local Food: A Review." Food Quality and Preference 40: 152-164.

Fonner, R., and G. Sylvia. 2015. "Willingness to Pay for Multiple Seafood Labels in a Niche Market." Marine Resource Economics 30: 51-70.

Giorda, E. 2018. "Boutique Food Producers at The Detroit Eastern Market: The Complex Identities of Authentic Food." Agriculture and Human Values 35: 747-760.

Gumirakiza, J., K. Curtis, and R. Bosworth. 2017. "Consumer Preferences and Willingness to Pay for Bundled Fresh Produce Claims at Farmers' Markets." Journal of Food Products Marketing 23: 61-79.

Harmon, B., C. Blake, C. Armstead, and J. Hébert. 2013. "Intersection of Identities. Food, Role, and the African-American Pastor." Appetite 67: 44-52.

Hauser, D.J., and N. Schwarz. 2016. "Attentive Turkers: MTurk Participants Perform Better on Online Attention Checks than do Subject Pool Participants." Behavior Research Methods 48: 400-407.

Hensher, D.A., J.M. Rose, and W.H. Greene. 2015. Applied Choice Analysis. Cambridge: Cambridge University Press.

Hitlin, P. 2016. "Research in the Crowdsourcing Age: A Case Study." Pew Research Center: Available at: https://www.pewinternet.org/2016/07/11/research-in-the-crowdsourcing-age-a-case-study/.

Hu, W., Batte M.T., T. Woods, and S. Ernst. 2012. "Consumer Preferences for Local Production and Other Value-Added Label Claims or a Processed Food Product." European Review of Agricultural Economics 39: 489-510.

Hu, W., T. Woods, and S. Bastin. 2009. "Consumer Acceptance and Willingness to Pay for Blueberry Products with Nonconventional Attributes." Journal of Agricultural and Applied Economics 41: 47-60.

Jensen, L.A., J.J. Arnett, and J. McKenzie. 2011. "Globalization and Cultural Identity." In S. J. Schwartz, K. Luydckx, and V. L. Vignoles (Eds.), Handbook of Identity Theory and Research (pp. 285-301). New York: Springer.

Johnson, C., J. Sharkey, W. Dean, W. McIntosh, and K. Kubena. 2011. "It's Who I am and What We Eat. Mothers' Food-Related Identities in Family Food Choice." Appetite 57: 220-228. 
Khachatryan, H., A. Rihn, B. Campbell, B. Behe, and C. Hall. 2018. "How Do Consumer Perceptions Of "Local" Production Benefits Influence Their Visual Attention to State Marketing Programs? Agribusiness 34: 390-406.

Laudan, R. 2013. Cuisine and Empire: Cooking in World History. University of California Press.

Khanal, B., R.A. Lopez, and A.M. Azzam. 2018. "Local Bias in Fluid Milk Consumption." In 2018 Annual Meeting, August 5-7, Washington, DC. No. 274142. Agricultural and Applied Economics Association, 2018.

Li, X., K. Jensen, D. Lambert, and C. Clark. 2018. "Consequentiality Beliefs and Consumer Valuation of Extrinsic Attributes in Beef." Journal of Agricultural and Applied Economics 50: 1-26.

Loureiro, M., and S. Hine. 2002. "Discovering Niche Markets: A Comparison of Consumer Willingness to Pay for Local (Colorado Grown), Organic, and GMO-Free Products.” Journal of Agricultural and Applied Economics 34: 477-487.

Low, S.A., A. Adalja, E. Beaulieu, N. Key, S. Martinez, A. Melton, A. Perez, K. Ralston, H. Stewart, S. Suttles, and B.B. Jablonski. 2015. "Trends in U.S. Local and Regional Food Systems: A Report to Congress." U.S. Department of Agriculture, Economic Research Service.

Lusk, J.L. 2017. "Consumer Research with Big Data: Applications from the Food Demand Survey (FooDS)." American Journal of Agricultural Economics 99: 303-320.

Malone, T., and F. Norwood. 2019. "Gluten Aversion is not Limited to the Political Left." Agriculture and Human Values EarlyCite: 1-15.

Mason, W., and S. Suri. 2012. "Conducting Behavioral Research on Amazon's Mechanical Turk." Behavior Research Methods 44: 1-23.

Master, K.T., J. LaChance, S. Bowen, and L. MacNell. 2019. “Terroir in Transition: Environmental Change in the Wisconsin Artisanal Cheese and New England Oyster Sectors." Sustainability 11: 1-23.

McFadden, D. 1973. “Conditional Logit Analysis of Qualitative Choice Behavior.” In P. Zarembka (Ed.), Frontiers in Econometrics (pp. 105-142). New York: Academic Press.

Meas, T., W. Hu, M.T. Batte, T.A. Woods, and S. Ernst. 2015. "Substitutes or Complements? Consumer Preference for Local and Organic Food Attributes.” American Journal of Agricultural Economics 97: 1044-1071.

Merritt, M., K. Delong, A. Griffith, and K. Jensen. 2018. "Consumer Willingness to Pay for Tennessee Certified Beef." Journal of Agricultural and Applied Economics 50: 233-254.

Murcott, A., W. Belasco, and P. Jackson. 2013. The Handbook of Food Research. London: Bloomsbury Publishing.

Nganje, W., R. Shaw Hughner, and N. Lee. 2011. "State-Branded Programs and Consumer Preference for Locally Grown Produce." Agricultural and Resource Economics Review 40: 20-32.

O’Kane, G. 2016. “A Moveable Feast: “Contemporary Relational Food Cultures Emerging from Local Food Networks.” Appetite 105: 218-231.

Onozaka, Y., and D.T. McFadden. 2011. "Does Local Labeling Complement or Compete with Other Sustainable Labels? A Conjoint Analysis of Direct and Joint Values for Fresh Produce Claim." American Journal of Agricultural Economics, 93: 689-702.

Printezis, I., and C. Grebitus. 2018. "Marketing Channels for Local Food.” Ecological Economics 152: 161171.

Printezis, I., C Grebitus, and S Hirsch. 2019. “The Price is Right!? A Meta-Regression Analysis on Willingness to Pay for Local Food.” PLoS ONE, 14.

Quintero-Angel, M., D. Mendoza, and D. Quintero-Angel. 2019. “The Cultural Transmission of Food Habits, Identity, and Social Cohesion: A Case Study in The Rural Zone of Cali-Colombia.” Appetite 139: $75-83$.

Richards, T.J., S.F. Hamilton, M. Gomez, and E. Rabinovich. 2017. "Retail Intermediation and Local Foods." American Journal of Agricultural Economics 99: 637-659.

Sackett, H., R. Shupp, and G. Tonsor. 2016. "Differentiating "Sustainable" From "Organic" and "Local" Food Choices: Does Information about Certification Criteria Help Consumers? International Journal of Food and Agricultural Economics 4: 17-31.

Schmitt, E., B. Dominique, and J. Six. 2018. "Assessing the Degree of Localness of Food Value Chains." Agroecology and Sustainable Food Systems 42: 573-598.

Schnell, S., and J. Reese. 2003. "Microbreweries as Tools of Local Identity." Journal of Cultural Geography 21: 45-69. 
Stephenson, G., and L. Lev. 2004. "Common Support for Local Agriculture in Two Contrasting Oregon Communities." Renewable Agriculture and Food Systems 19: 210-217.

Thilmany, D., C. Bond, and J. Bond. 2008. "Going Local: Exploring Consumer Behavior and Motivations." American Journal of Agricultural Economics 90: 1303-1309.

Thilmany, D., and T.A. Woods. 2018. "Local Food Coming of Age: The Evolution of the Local Brand, Policy Initiatives and Role of Direct Markets in the Agriculture Portfolio." Choices 33: 1-2.

Tookes, J.S., P. Barlett, and T. Yandle. 2018. "The Case for Local and Sustainable Seafood: A Georgia Example." Culture, Food, Agriculture and Environment 40: 55-64.

U.S. Census Bureau.. 2019. American Fact Finder. From https://factfinder.census.gov/faces/tableservices/ jsf/pages/productview.xhtml?src=bkmk

Willis, D., C. Carpio, and K. Boys. 2016. "Supporting Local Food System Development Through Food Price Premium Donations: A Policy Proposal." Journal of Agricultural and Applied Economics 48: 192-217.

Yue, C., and C. Tong. 2009. "Organic or Local? Investigating Consumer Preference for Fresh Produce Using a Choice Experiment with Real Economic Incentives." HortScience 44: 366-371. 
Appendix

Table A1. Local Foods Willingness to Pay

\begin{tabular}{|c|c|c|c|c|}
\hline Authors & Location & Sample size & Product & Processing? \\
\hline Bernard and Liu (2017) & $\mathrm{DE}$ & 122 & Apple & No \\
\hline Brown (2003) & MO, TN & 544 & Fruits, vegetables & No \\
\hline Bruno and Campbell (2016) & CT & 288 & Meals & Yes \\
\hline Carpio and Isengildina-Massa (2009) & SC & 500 & Produce, meats & No \\
\hline Chen et al. (2017) & $\mathrm{HI}$ & 27 & Oysters & No \\
\hline Costanigro et al. (2011) & $\mathrm{CO}$ & 299 & Apples & No \\
\hline Costanigro et al. (2014) & $\mathrm{CO}$ & 109 & Apples & No \\
\hline Darby et al. (2008) & $\mathrm{OH}$ & 530 & Strawberries & No \\
\hline Fonner and Sylvia (2015) & OR & 500 & Tuna, salmon, sole, shrimp, crab & No \\
\hline Gumirakiza et al. (2017) & UT & 819 & Peaches, squash, eggplant & No \\
\hline Hu, Woods, and Bastin (2009) & KY & 557 & Blueberry jam, yogurt, dry muffin mix, raisinettes & Yes \\
\hline Hu et al. (2012) & $\mathrm{KY}, \mathrm{OH}$ & 1884 & Blackberry jam & Yes \\
\hline Khachatryan et al. (2018) & $\mathrm{FL}$ & 87 & Blueberry, pineapple, kiwi & No \\
\hline Khanal et al. (2018) & New England & 7,121 & Milk & Yes \\
\hline
\end{tabular}




\begin{tabular}{llcll} 
Li et al. (2018) & USA & 1688 & Steak, ground beef & No \\
\hline Loureiro and Hine (2002) & CO & 437 & Potatoes & No \\
\hline Meas et al. (2015) & KY, OH & 1883 & Blackberry jam & Yes \\
\hline Merritt et al. (2018) & TN & 408 & Steak, ground beef & No \\
\hline Nganje, Shaw Hughner, and Lee (2011) & AZ & 315 & Spinach, carrots & No \\
\hline Onozaka and McFadden (2011) & USA & 1052 & Apples, tomatoes & No \\
\hline Printezis and Grebitus (2018) & AZ, MI & 1046 & Tomatoes & No \\
\hline Richards et al. (2017) & VA & 12409 & Bananas, apples, grapes, oranges & No \\
\hline Sackett, Shupp, and Tonsor (2016) & USA & 1002 & Apple, steak & Both \\
\hline Stephenson and Lev (2004) & OR & 315 & Fruits, vegetables, proteins, wine & No \\
\hline Thilmany Bond, and Bond (2008) & USA & 1549 & Melons & No \\
\hline Tookes, Barlett, and Yandle (2018) & GA & 500 & Shrimp, finfish, crabs, mussels, oysters, clams \\
\hline Willis Carpio, and Boys (2016) & SC & 340 & Produce, meats & No \\
\hline Yue and Tong (2009) & MN & 365 & Tomatoes & No \\
\hline
\end{tabular}


Table A2. Price Levels for Discrete Choice Experiment Alternatives

\begin{tabular}{lc}
\hline Alternative & Price Levels \\
\hline Cherries & $7.24,11.74$ \\
\hline Grapes & $1.99,3.99$ \\
\hline Strawberries & $2.99,4.99$ \\
\hline Blackberries & $2.49,5.49$ \\
\hline
\end{tabular}

Cite this article: Moreno F, Malone T (2021). The Role of Collective Food Identity in Local Food Demand. Agricultural and Resource Economics Review 50, 22-42. https://doi.org/10.1017/age.2020.9 